\title{
Our emperors have no clothes
}

\section{The ITER fusion project demonstrates a solidity of purpose that is sorely lacking across the rest of the energy research spectrum.}

ast week's formal agreement in Paris to begin construction of the ITER experimental fusion reactor at Cadarache in France -was a satisfying culmination of decades of effort by the fusion community. The project may or may not ensure the technical future of magnetic fusion energy, but it will certainly provide an invaluable focal point for its investigation for decades to come.

The agreement to build ITER - which, in a landmark move, includes significant contributions from both India and China - is out of character, however. There is no corresponding effort, collaborative or otherwise, to do the research that is needed to aggressively pursue any of the other multifarious approaches to tackling the mounting global energy crisis.

Energy research and development has actually collapsed since the aftermath of the last energy crisis in the 1970s. Indeed, according to an assessment by the Pacific Northwest National Laboratory in Washington state, global expenditure on it has fallen by two-thirds since 1974. This time, climate change and a vast upsurge in the Asian demand for energy, as well as a crisis in the Middle East, mean it is almost universally acknowledged that the energy crisis is here to stay. But there is still no serious effort to revive energy research.

The reasons (or excuses) for inaction vary from place to place. One universal theme lurking in the background is the belief that market forces will pull viable energy sources to fruition, without the need for publicly supported research. Oddly enough, this argument doesn't stop governments supporting basic and applied research in areas such as public health, where they perceive a pressing need to push technology forward into the market. In any case, market forces are largely absent, as most users of fossil fuel still don't pay the real cost of their carbon emissions.

\section{Energy research}

It is true that the short-term economic feasibility of renewable energy sources, for example, or of clean-burning coal-fired power stations, will be determined largely by market conditions. However, in the longer term, radical breakthroughs in everything from photovoltaic materials to the efficiency of cars and trucks are critically important to the prospects for different approaches to energy production, transmission and use.

Over the past 30 years, only Japan, which is dependent on imported fossil fuels, has maintained energy research at a reasonably high level. And even Japan's programme is seriously skewed in favour of approaches to nuclear fission that look increasingly unlikely to meet its energy needs.

In the United States, energy research at least has a natural home, in the Department of Energy. The department's research programmes have some notable strengths: its basic energy-sciences programme, for example, supports a raft of basic research projects and facilities in fields, such as materials science, that may underpin future progress in energy technologies. Its network of national laboratories provides a good interdisciplinary foundation for both basic and applied energy research. And its research efforts in energy conservation have grown over the past decade. However, its investment in research on renewable energy remains tiny, especially compared with the levels that were briefly attained under Jimmy Carter's presidency. On energy policy, as on other matters, Carter's legacy continues to improve with age. If the new Democratic majority in Congress is serious about energy policy, it will do its best to restore these programmes.

\section{Underfunding and neglect}

In Europe, energy research programmes have been eviscerated since the 1970s, despite political leaders' claims to be taking climate change seriously. The nuclear fission programmes that dominated at that time have been abandoned (except in France), and nothing has been established in their place. Applied energy research has no natural institutional home and no clear political constituency (in the shape of a group of dependent institutions or individuals who will fight for its budget). With the exception of fusion and ITER, the overall European effort is paltry, and is mainly based in universities - which are good at identifying ideas, but are not equipped to take them forward into commercial application.

Some proposals have been developed to confront this. Germany is spending $€ 50$ million (US\$65 million) each year at the European Institute for Energy Research at Karlsruhe, and Britain is planning to spend a similar amount (matched by private funds) at an Energy Technology Institute, to be established in 2008. The seventh European Framework Programme, which starts next year, identifies energy as one of nine priorities (transportation is another),
"In Europe, energy research programmes have been eviscerated, despite political leaders' claims to be taking climate change seriously."

but devotes less than $5 \%$ of its total resources - $€ 2.3$ billion over six years - to its pursuit.

None of this is commensurate with the immense challenges of energy security and climate change facing the world. The ITER project, admirable though it is, should be merely a component of a concerted effort. Fusion is decades away from fruition, and even its proponents don't expect it to contribute to the world's need for alternatives to fossil fuel within the next 30 years.

Fusion is also unusual in that its prototyping needs a multibilliondollar facility that can best be built through a fully fledged international collaboration. Other energy research has infrastructure requirements, too. But most of the parties to the ITER agreement are neglecting them, allowing energy research and development to drift along listlessly. In so doing, they betray an appalling lack of seriousness in confronting one of the century's most pressing problems. 